\title{
Cuidado de enfermagem às crianças com leucemia em um hospital de alta
}

\section{complexidade}

Nursing care for children with leukemia in a high complexity hospital

Atención de enfermería al niño con leucemia en un hospital de alta complejidad

Anna Priscylla da Costa Oliveira

ORCID: https://orcid.org/0000-0001-9364-8049

Centro Universitário Maurício Nassau, Brasil E-mail: Anna_Priscyllaa@hotmail.com

Rosane da Silva Santana

ORCID: https://orcid.org/0000-0002-0601-8223 Universidade Federal do Ceará, Brasil E-mail: rosane_santana5@hotmail.com

Ana Cristina Ferreira Pereira

ORCID: https://orcid.org/0000-0002-8429-5496 Instituto de Medicina Integral Fernando Figueira, Brasil E-mail: annicris874@gmail.com

Wesley Brandolee Bezerra Fernandes ORCID: https://orcid.org/0000-0003-1472-1207 Instituto de Ensino Superior Múltiplo, Brasil E-mail: w.brandolee@outlook.com

Luana Miranda de Almeida

ORCID: https://orcid.org/0000-0002-2541-2330

Centro Universitário UniFacid Wyden, Brasil E-mail: anaul_mir@hotmail.com

Janaína Freitas Leal

ORCID: https://orcid.org/0000-0001-8495-4247

Centro Universitário Maurício de Nassau, Brasil E-mail:janaleslei@gmail.com

Amélia Rosa de Assis

ORCID: https://orcid.org/0000-0002-0478-9008

Centro Universitário UniFacid Wyden. Brasil

E-mail: amelinharosa25@gmail.com

Álesson Marlon Silva da Luz

ORCID: https://orcid.org/0000-0002-2684-3669

Centro Universitário Maurício de Nassau, Brasil

E-mail: allesson.luz@gmail.com

Joelma da Silva Porto

ORCID: https://orcid.org/0000-0002-3374-2719

Centro Universitário Maurício de Nassau, Brasil

E-mail: jportosantana@gmail.com

Maria do Amparo Ferreira Santos e Silva

ORCID: https://orcid.org/0000-0003-3758-4778 Hospital Universitário do Piauí, Brasil E-mail: enfamparofss@hotmail.com

Elane Rodrigues Sales

ORCID: https://orcid.org/0000-0002-6310-7978 Faculdade do Meio Norte (FAEME), Brasil E-mail: elaneflad@gmail.com

Yarlla Alcântara Vitório de Oliveira

ORCID: https://orcid.org/0000-0003-1644-9614 Unidades Integradas de Pós-graduação, Brasil E-mail: Yarlla_2@hotmail.com

\section{Resumo}

Introdução: O câncer infantil é considerado uma doença rara, sendo progressiva e de grande relevância à saúde pública no país. Quando associado aos tumores, a leucemia é considerada a segunda causa de mortalidade principalmente na faixa etária de cinco a nove anos. A atuação do enfermeiro tem papel primordial na recuperação e na manutenção das condições saudáveis de vida da criança. Objetivo: Conhecer os cuidados prestados pela enfermagem às crianças com leucemia no ambiente hospitalar. Metodologia: Trata-se de uma pesquisa qualitativa de 
abordagem descritiva. Foi realizada na clínica oncológica pediátrica de um hospital filantrópico em Teresina-PI. Os sujeitos da pesquisa foram todos os enfermeiros e sete técnicos em enfermagem. Os dados foram colhidos nos meses de setembro a novembro de 2017, por meio de um roteiro de entrevista semiestruturada. Resultado: Participaram do estudo três enfermeiros e sete técnicos em enfermagem e, a partir dos relatos emergiram duas categorias temáticas: $\mathrm{O}$ acolhimento de enfermagem à criança com leucemia durante a internação; O incentivo da enfermagem para que as crianças com leucemia permaneçam internadas até a recuperação. Evidencia-se a utilização de estratégias para proporcionar bem-estar do binômio criança/família por meio do acolhimento em conjunto com a assistência humanizada; orientações quanto aos procedimentos que terão de passar no ambiente hospitalar; apoio aos familiares e a promoção do lazer da criança, horário para brincar. Conclusão: Este estudo contribuiu na ampliação dos conhecimentos da enfermagem sobre os cuidados prestados às crianças com leucemia, bem como na discussão e implementação de ações que possam promover a melhoria da qualidade de vida dessas crianças.

Palavras-chave: Criança; Cuidados; Enfermagem; Leucemia.

\begin{abstract}
Introduction: Childhood cancer is considered a rare disease, being progressive and of great relevance to public health in the country. When associated with tumors, leukemia is considered to be the second leading cause of mortality mainly in the age group of five to nine years. The role of the nurse has a primary role in the recovery and maintenance of the child's healthy life conditions. Objective: To know the care provided by nursing to children with leukemia in the hospital environment. Methodology: This is a qualitative research with a descriptive approach. It was performed at the pediatric oncology clinic of a philanthropic hospital in Teresina-PI. The research subjects were all nurses and seven nursing technicians. Data were collected from September to November 2017, using a semi-structured interview script. Result: Three nurses and seven nursing technicians participated in the study and, from the reports, two thematic categories emerged: Nursing care for children with leukemia during hospitalization; Nursing incentive for children with leukemia to remain hospitalized until recovery. It is evident the use of strategies to provide well-being of the child / family binomial through welcoming together with humanized assistance; guidance on the procedures they will have to undergo in the hospital environment; support for family members and promotion of children's leisure, time to play. Conclusion: This study contributed to the expansion of nursing knowledge about the care provided to children with leukemia, as well as in the discussion and implementation of actions that can promote the improvement of the quality of life of these children.
\end{abstract}

Keywords: Child; Care; Nursing; Leukemia.

\title{
Resumen
}

Introducción: El cáncer infantil es considerado una enfermedad rara, progresiva y de gran relevancia para la salud pública del país. Cuando se asocia con tumores, la leucemia se considera la segunda causa principal de mortalidad, principalmente en el grupo de edad de cinco a nueve años. El papel de la enfermera tiene un papel primordial en la recuperación y mantenimiento de las condiciones de vida saludables del niño. Objetivo: Conocer los cuidados que brinda la enfermería al niño con leucemia en el ámbito hospitalario. Metodología: Se trata de una investigación cualitativa con enfoque descriptivo. Se realizó en la clínica de oncología pediátrica de un hospital filantrópico de Teresina-PI. Los sujetos de investigación fueron todos enfermeros y siete técnicos de enfermería. Los datos se recopilaron de septiembre a noviembre de 2017, utilizando un guión de entrevista semiestructurado. Resultado: Participaron del estudio tres enfermeros y siete técnicos de enfermería y de los informes surgieron dos categorías temáticas: Atención de enfermería al niño con leucemia durante la hospitalización; Incentivo de enfermería para que los niños con leucemia permanezcan hospitalizados hasta la recuperación. Es evidente el uso de estrategias para brindar bienestar al binomio niño / familia a través de la acogida y la asistencia humanizada; orientación sobre los procedimientos a los que deberán someterse en el entorno hospitalario; apoyo a los familiares y promoción del ocio infantil, tiempo para jugar. Conclusión: este estudio contribuyó a la expansión del conocimiento de enfermería sobre el cuidado brindado a los niños con leucemia, así como en la discusión e implementación de acciones que puedan promover la mejora de la calidad de vida de estos niños.

Palabras clave: Niño; Cuidado; Enfermería; Leucemia.

\section{Introdução}

Na infância, a leucemia é considerada um dos tipos mais comuns de câncer na faixa pediátrica. É um grande desafio para os profissionais de saúde, familiares e o próprio paciente. Considerada uma doença maligna dos glóbulos brancos (leucócitos), geralmente de origem desconhecida. Origina-se nos tecidos que produzem o sangue na medula óssea, podendo ser aguda ou crônica (Brasil, 2013). 
A leucemia apresenta percentual de 2\% a 3\% na maioria da população infantil. É considerada como sério problema de saúde pública pela alta complexidade e morbimortalidade que causa. Em crianças, este tipo de câncer, é diferente da pessoa adulta, em decorrência da histologia, do comportamento clínico e do topográfico da patologia (Silva, Moreira-Filho \& Thofehrn, 2012).

É uma doença hematológica que acomete indivíduos de todas as faixas etárias, tendo como umas das características em comum a proliferação descontrolada de células anormais que pode ocorrer em qualquer parte do organismo (Brasil, 2016).

A doença apresenta curtos períodos de latência, tornando-se mais agressiva e com progressão rápida. $\mathrm{O}$ surgimento da patologia pode ocorrer em qualquer faixa etária, em ambos os sexos e ter diferentes causas, manifestações clínicas, tratamentos e prognósticos sendo que, muitas vezes, este diagnóstico ocasiona o medo, sofrimento e angústia à criança e à sua própria família (Brasil, 2012).

A leucemia na forma aguda caracteriza-se pelo crescimento rápido das células jovens, fazendo com que a medula seja incapacitada de produzir células novas. Já a crônica resulta do crescimento exacerbado das células brancas maduras anormais, levando muito tempo para progredir. E quanto ao tipo celular, causada pelas desordens genéticas, pode ser do tipo mieloide ou linfoide (Brasil, 2016).

Apesar dos avanços na terapia oncológica, a leucemia ainda se apresenta como uma doença de prognóstico relacionado ao medo da morte, sobrecarregada de sofrimentos que afeta não apenas às crianças, mas toda família, pelo estigma que acompanha. Quando a criança é diagnosticada com câncer, geralmente afeta a estrutura familiar, gerando conflitos e impactos pelos os mitos da doença oncológica na sociedade, influenciando, negativamente no processo de aceitação da doença (Duarte, Zanini \& Nedel, 2012).

O diagnóstico da leucemia pode ocasionar, também, outros grandes desafios para os profissionais de saúde, pois eles tornam-se fundamentais pelo suporte assistencial e psicológico que dão a essas crianças e, em virtude de diversas situações patológicas, algumas modificações importantes podem ocorrer na rotina desses pacientes, uma vez que a leucemia pode acabar gerando muita ansiedade à resposta clínica do tratamento (Demirbag, Kurtuncu \& Guven, 2013).

No tratamento da leucemia, a quimioterapia é a terapêutica de escolha. As crianças precisam estar hospitalizadas para o atendimento de suas possíveis intercorrências de saúde, devido aos efeitos esperados e adversos que podem as debilitar física e emocionalmente. Geralmente, durante o tratamento, o paciente fica imunodeprimido e pode ter comprometimento de suas defesas orgânicas ocasionando anemia, leucopenia e plaquetopenia, expondo-o a infecções oportunistas. Nesse contexto, faz-se necessário o isolamento protetor (Viero et al., 2014).

Para adaptar-se ao novo ambiente em que a criança está inserida, o familiar precisa ser informado sobre os cuidados a serem realizados com a criança de acordo com as alterações do sistema imunológico. A educação em saúde é uma forma de orientar e solucionar as dúvidas a respeito do isolamento protetor, pois entende-se que o familiar sem informações pode exercer grande influência sobre o paciente e o andamento do tratamento a ser realizado (Bellesso, 2013).

O cuidado à criança com leucemia é bastante complexo, pois envolve múltiplos aspectos em relação ao tratamento adequado, por isso é importante que o profissional enfermeiro articule conhecimento técnico e científico, contemplando um diferencial no que se refere à afetividade em oferecer um cuidado buscando a promoção da saúde, a qualidade de vida da criança, o conforto e o bem-estar (Silva et al., 2013)

Com o aumento da gravidade da leucemia, é imprescindível que as crianças sejam acompanhadas rotineiramente. Devem fazer exames específicos para detecção precoce de algumas complicações oriundas da doença. Para tanto, os profissionais de saúde, especificamente a enfermagem, devem estar atentos aos cuidados mais adequados na minimização das diversas complicações que o tratamento da leucemia pode ocasionar (Souza et al., 2013a). 
As ações de enfermagem são fundamentais para o tratamento e recuperação da criança. É necessário que a enfermagem seja capacitada para promover cuidados com qualidade (Andrade, Sawada \& Barichello, 2013).

A enfermagem tem como meta oferecer as crianças segurança e confiança, identificando os obstáculos que o paciente possui para tomar conduta correta e obter êxito em sua assistência. Deve agir na implementação e operacionalização de ações que visem à sistematização do cuidado individual e integral ao cliente e a comunidade com medidas interventivas e propiciadoras da promoção da saúde (Cunha et al., 2013).

A atuação da equipe de enfermagem não deve ser baseada apenas na aplicação de conhecimentos técnico-científicos, mas em habilidades e cuidados humanísticos, envolvendo todo contexto psicossocial do cliente, mensurando a dor, o medo, a depressão, a ansiedade e sentimentos vividos pela criança em tratamento oncológico (Maranhão, 2011).

Este estudo teve como objetivo analisar os cuidados prestados pela enfermagem às crianças com leucemia. A evidência cientifica no cuidado às crianças durante o tratamento é fundamental para o prognóstico positivo. É necessária avaliação do cuidado para que medidas efetivas sejam implementadas para uma assistência de qualidade.

\section{Metodologia}

Trata-se de uma pesquisa qualitativa, descritiva. A pesquisa foi realizada nos meses de setembro a novembro de 2017 na clínica oncologia de um hospital privado de alta complexidade situado no município de Teresina - PI, após a aprovação da Comissão de Ética do hospital e posterior autorização do Comitê de Ética e Pesquisa com o Parecer nº 2274458.

Participaram da pesquisa três enfermeiros e sete técnicos em enfermagem. Foram incluídos os enfermeiros que trabalham na clínica oncológica há mais de um ano nos turnos, manhã, tarde e noite. E excluídos, os que se encontravam de férias, licença e vacância durante o período da coleta de dados.

Para coleta de dados, utilizou-se a técnica de entrevista, por meio de um roteiro semiestruturado. A primeira parte do instrumento foi constituída por questões pertinentes à caracterização demográfica dos participantes, incluindo as variáveis sexo, idade, tempo de formação profissional. A segunda parte constou de duas questões norteadoras, abertas, que visavam obter dados pertinentes às ações dos enfermeiros na oncologia. Os sujeitos participantes receberam explicações sobre os objetivos e os procedimentos que foram utilizados na pesquisa, com o detalhamento dos métodos a serem utilizados, os desígnios dos dados que foram coletados, além dos benefícios esperados dessa participação.

Para garantir a ética que rege a pesquisa científica com seres humanos, o sigilo e o anonimato dos participantes foram preservados. Os enfermeiros e os técnicos em enfermagem que participaram da pesquisa foram identificados, respectivamente, pela letra E e T, seguidos de um algarismo arábico na sequência de realizações da entrevista.

A partir do consentimento dos profissionais de enfermagem, foi agendado o horário para a aplicação da entrevista semiestruturada conforme a disponibilidade de cada participante. Para que nenhuma informação relevante fosse perdida ou esquecida, foi utilizado como recurso um aparelho móvel (mp4) objetivando garantir a autenticidade dos depoimentos representados pela fala dos entrevistados para consecutivamente serem transcritas na íntegra.

\section{Resultados e Discussão}

\subsection{Caracterizações dos sujeitos}

Os sujeitos da pesquisa foram três enfermeiros e sete técnicos em enfermagem. Dos três enfermeiros, dois são do sexo feminino e um masculino com idades entre 23 a 29 anos. Apenas dois enfermeiros possuem especialização em oncologia pediátrica. Quanto aos técnicos de enfermagem todos são do sexo feminino com idades entre 22 a 45 anos. 
Research, Society and Development, v. 10, n. 3, e14410313142, 2021

(CC BY 4.0) | ISSN 2525-3409 | DOI: http://dx.doi.org/10.33448/rsd-v10i3.13142

\subsection{Categorias analíticas}

\section{Categoria 1: $O$ acolhimento de enfermagem à criança com leucemia durante a internação}

Uma assistência acolhedora e resolutiva repercute na qualidade do cuidado, favorecendo a formação do vínculo entre o binômio criança/família e profissionais de saúde. Porém, para que essas famílias se sintam acolhidas e os conflitos sejam amenizados, os profissionais de saúde, principalmente os de enfermagem, que são os profissionais do cuidar, devem ser sensíveis à realidade desses cuidados (Ribeiro, Gomes \& Thofehrn, 2014).

Compreender suas demandas, singularizar o cuidado de acordo com cada paciente, fazer do paciente um sujeito ativo no processo terapêutico proporcionam a criação do vínculo e consolidam o acolhimento de forma eficaz e representativa para ambos, o ser que cuida e ser cuidado (Pereira, Matsue, Vieira \& Pereira, 2014).

Existem vários pontos positivos quando o acolhimento é realizado com eficiência, por exemplo: a família manifesta confiança, a terapia é mais aceita e torna-se menos dolorosa, as dúvidas são sanadas, a ansiedade diminui, ou seja, o ato de acolher promove satisfação entre os envolvidos. O profissional de saúde pode contar com a família e a família transforma o profissional em fonte de apoio (Maestri, Nascimento, Bertoncello \& Jesus Martins, 2012).

Quanto às falas dos entrevistados, observou-se que maioria descreve um acolhimento humanizado, havendo respeito à autonomia nas escolhas da criança e da mãe, ajuda multiprofissional, orientação sobre as rotinas e assistência que serão realizadas naquele ambiente.

Quando a criança chega geralmente ela vem só com um pré-diagnostico aqui é feito todo os exames de diagnósticos, mais assim, a gente já recebe a criança a parte de enfermagem, a gente trabalha com a equipe multi profissional tanto com a parte de psicólogo, como de enfermeiro, tem uma terapeuta ocupacional, mais ela está afastada por conta da licença maternidade, como da equipe médica como da equipe de enfermagem a gente se apresenta, tem toda aquela acolhida com o paciente, da toda assistência. (E01)

Destaca-se, na fala acima, a importância que a enfermagem dar ao trabalho conjunto com equipe multiprofissional. A assistência multiprofissional articulada repercute positivamente na qualidade de vida da criança e sua família. Segundo Gurgel e Lage (2013), a prática do psicólogo no contexto do câncer infantil é voltada para o aconselhamento, apoio e reabilitação da criança e da família, podendo ser realizada de forma nível individual ou grupal por meio do esclarecimento de dúvidas, escuta qualificada e mediação entre paciente-família-equipe.

Com relação a atuação da enfermagem, ela deve atuar de modo a auxiliar no processo da doença, tanto a criança quanto a família, através de uma assistência integral. Por estar em contato constante com o paciente e sua família, os profissionais de enfermagem desenvolvem a sensibilidade de perceber e reconhecer sinais de alerta para o agravamento da doença possibilitando, assim, a prevenção de agravos (Matias, 2016).

No discurso a seguir (E02), percebe-se que a ideia de acolhimento com às crianças é um pouco confusa uma vez que a participante afirma que essa ação é realizada igual ao de um adulto e, na maioria das vezes, quando tem a criança apresenta intercorrências. Deixando a desejar na qualidade da assistência prestada a um público que necessita, principalmente, de compreensão, acolhida e respeito as suas singularidades como cliente.

Assim, é tudo igual ao adulto. Não entendi essa tua pergunta como é feito o acolhimento, é normal depende da idade da criança, quando é muito pequeno é feito com a mãe né, não tem como a gente fazer com a criança, a gente faz 
Research, Society and Development, v. 10, n. 3, e14410313142, 2021

(CC BY 4.0) | ISSN 2525-3409 | DOI: http://dx.doi.org/10.33448/rsd-v10i3.13142

aquele tratamento, é, conversa com não tem tratamento especifico não, é mais só conversa com a mãe, com a criança, mulher assim, a gente só vai mais quando tem intercorrência. (E02)

A entrevista acima, destaca a mãe como alvo de acolhimento quando a criança ainda é pequena. A respeito da condição de acompanhante, a literatura aponta a mãe como o familiar que mais está presente junto os pacientes enfermos com doença crônica, aumentando assim o seu papel, que já envolve o cuidado do lar, da família e das pessoas doentes. E, com relação ao câncer a situação não é diferente, elas se dedicam totalmente aos cuidados com seus filhos. Logo, o abalo psicológico é visível necessitando ser inserida no processo terapêutico juntamente com a criança (Miranda \& Aravena, 2012).

Ressalta-se, que o acolhimento vai desde a internação à alta da criança/família, considera todas as fases da terapêutica do câncer, a saber: diagnóstico, tratamento e cura ou cuidados paliativos. Verifica-se, no relato a seguir, que a enfermagem apresenta o diagnóstico como fase mais complexa do processo de adoecimento pelo câncer, por se tratar do primeiro contato com a doença.

[...] Nossa equipe age junto com a psicóloga, por que assim sempre que o paciente interna ele vai ter aquele diagnostico, então vai ser aquele primeiro contato dele com a doença, então é muita coisa, assim, tanto para a família, quanto para o paciente e muito complicado [...]. [...]. Assim, para a criança e muito doloroso, por que não é feito no centro cirúrgico, ele é feito na salinha de exames que a gente tem, apesar de da anestesia local, mais para a criança é bem mais difícil, então assim, a gente tenta antecipar para a criança, e para o acompanhante o que vai acontecer com ela durante a internação[...]. (E03)

Realizamos o processo de acolhimento com a humanização, por serem crianças o processo de adaptação é maior e o processo de socialização com a equipe de enfermagem é mais demorado. (T01)

O paciente oncológico é um ser humano suscetível a crises de caráter psicológico, biológico, social ou espiritual que podem ser desencadeadas pelo diagnóstico, prognóstico e efeitos colaterais do tratamento. Dessa forma, entender o impacto do câncer no paciente é essencial para estabelecer estratégias de cuidados (Silva \& Hortale, 2006).

O impacto do câncer no público infantil pode ser verificado nos sentimentos expressados, a saber: medo da morte, as dores, o retraimento e revolta com os procedimentos, a tristeza diante das limitações impostas pela doença e a angústia perante as incertezas (Souza et al., 2012).

Como já descrito, conhecer esses sentimentos proporcionam a criação de estratégias que melhoram a assistência prestada à criança com câncer, repercutindo em um melhor processo de adaptação às mudanças ocorridas nessa trajetória de vida.

Na fala do T02 são descritos os cuidados realizados com às crianças com leucemia. Foram citados os cuidados desde o acolhimento, a preocupação em melhorar a ansiedade das crianças e das mães, até mesmo os cuidados mais complexos associados à patologia.

Pelo menos comigo eu priorizo muito a questão da humanização, por que como é criança eles vêm muito assustado, já vem com aquela coisa de meu deus e um hospital vão me furar, o primeiro pensamento deles é esse, e eu tento fazer de tudo para eles não sentirem isso[...]. [...] E daí a gente tenta sempre fazer com que o hospital não seja um vilão para eles, entendeu, porque aqui é muito difícil, a questão de receber criança, por que quando a gente recebe 
as vezes já está com um nível muito difícil, resumindo, é tentar ser mais humana possível e fazer com que eles esqueçam que está dentro de um hospital. (T02)

Para que o vínculo se torne maior que um ato profissional, um ato humano, Barbeiro (2013) diz ser necessário que a enfermagem esteja presente e sensibilizada a partilhar dos momentos de diagnóstico da doença, tratamento e na alta do paciente, apoiando a família em todos os momentos. Todavia, no estudo de Mutti et al. (2012), os profissionais de saúde expressam a conveniência em separar o profissional do emocional no cotidiano de cuidado à criança que tem câncer. Prevendo o sofrimento psicológico do profissional.

Ao reconhecer a equipe de enfermagem como profissionais que cuidam e precisam, também, ser cuidados. É indispensável o planejamento e estabelecimento de estratégias voltadas à equipe para a promoção do bem-estar psicológico.

A gente tenta esclarecer como é o início do tratamento com eles e assim, as próprias mães que já fazem o tratamento com as crianças ,elas já passa tudo aquilo ali pra outras mãe como é que funciona, se elas tiver alguma dúvida a gente souber a gente já esclarece, se não a gente já passa pra enfermeira e é assim, tentando com que ela aceite a situação e passando vários itens que é o cuidado de mão tá entrando em outras enfermarias, pra ela sempre ficar no leito dela, pra não ter contato com os outros por que tem alguns as vezes que tá com a imunidade baixa, estão com febre ou estão com algum tipo de bactéria, tem delas que entendem, tem delas que não entende que continuam tendo contato com os outros [...]. (T03)

[...] Ás vezes passa pela salinha de exames ás vezes não, quando passa pela salinha de exames já vem ou ás vezes eles nem vem puncionado, por que as vezes os meninos de lá nem punciona, as vezes e medicado, quando é pra ser medicado lá ai as vezes eles punciona quando não é mesmo assim eles sobem e punciona aqui, por que nem todos gostam de pegar veia de criança, ai aqui tem as pulseirinhas verde que e a de risco de queda são de grande importância[...]. (T04)

No relato acima, do T03, são citados os cuidados realizados com às crianças com leucemia desde a sua internação, evidencia-se ações pautadas na humanização, demostrando um cuidado ímpar e holístico.

Quando ele chega é bem complicado, eles vêm já do infantil né, as vezes nem vem com diagnostico ainda, aí vai ter a questão de investigação, é de exames as vezes, a maioria plaquetopenicos, essa questão de sangue, plaquetas é tudo muito novo ai elas ficam bem apreensivas né, as mães, essa questão também de acesso, ter que puncionar, puncionar, então eles ficam bem apreensivos também, com medo. (T05)

Tanto T05 como T06 citam os cuidados desde a admissão, o acolhimento, a preocupação em melhorar a ansiedade das crianças com relação à dor e a ansiedade das mães que ficam curiosas com relação os cuidados mais complexos associados a patologia. Nesses discursos, verifica-se que as informações e orientações repassadas pela equipe de enfermagem sobre os procedimentos e os cuidados a serem realizados favorecem na diminuição do impacto com o novo, diagnóstico do câncer.

A primeira coisa que a gente faz é se apresenta né, por que eles chegam com muito medo, eles chegam sem saber, a maioria das mães não sabem que existe essa ala aqui, não tem noção que existe crianças com esse tipo de doença, por que até acontecer com sua família, na sua casa, a pessoa não se integra das coisas, e quando chega um 
Research, Society and Development, v. 10, n. 3, e14410313142, 2021

(CC BY 4.0) | ISSN 2525-3409 | DOI: http://dx.doi.org/10.33448/rsd-v10i3.13142

diagnóstico desse, elas vem pra cá totalmente perdida, e as crianças mais ainda por que já vem de outro hospital, o acolhimento lá eu não sei como é que e feito, mais a maioria chega com uma visão feia da enfermagem, ai geralmente quando eles chegam aqui a gente procura acolher da melhor maneira possível, muito amor, muito carinho, primeiramente com a turma de enfermagem, a gente chama logo a psicologia, que junto com a gente fazer um trabalho, eu acho, aqui com as meninas que a gente cuida, excelente, trabalhando todo mundo junto, a gente procura se apresentar ,procurar dizer como é que faz os procedimentos, o que é que vai acontecer ,por que geralmente quando eles chegam aqui[...]. [...]. Aí tem que ser com muito amor, com muita calma, com muita explicação, para ver se eles têm uma aceitaçãozinha melhor em relação ao que vai ser realizado aqui na sala (T06).

Primeiro a gente recebe elas que ela vem lá da admissão do sus a gente olha a pulseirinha dela, se está identificada pergunta para a mãe, confere a pulseirinha com a mãe, leva até o leito, e vê como é que tá o psicológico dela, por que a primeira internação e sempre crítica, a gente vai logo direto com a psicóloga. (T07)

Dentre as repercussões trazidas pelo diagnóstico do câncer, de acordo com Gurgel e Lage (2013) um dos maiores impactos, de imediato, é o psicológico. Ao desencadear experiências de supressa, tensão, não aceitação diante a vários desafios como o mal prognóstico, os tipos de tratamento que serão submetidas, as restrições e os efeitos do tratamento.

No contexto do acolhimento, a enfermagem deve propor-se a prestar uma assistência que congregue técnica, ciência e humanização, tendo sempre em mente a importância do respeito às necessidades desses pacientes, ao atuar de uma forma humanizada, incluindo como cuidados não somente técnica, mas também o diálogo, saber ouvir, a segurança, a valorização das queixas e o apoio dos familiares.

\section{Categoria 2: $O$ incentivo da enfermagem para que as crianças com leucemia permaneçam internadas até a recuperação}

As mudanças na vida da criança e/ou adolescente doente e de sua família exigem uma readaptação diante da nova situação e as reações dependem das características e complexidade da doença, assim como, das formas de apoio que os paciente e familiares desenvolvem, pois, as mudanças fazem com que a família reestruture o seu cotidiano e reaprenda a cuidar do filho (a) e de si mesma.

Quando essa experiência é em decorrência da existência de um câncer, estas questões envolvem uma amplitude ainda maior no cenário do cuidado à criança, ao adolescente e sua família. Os profissionais de saúde devem ter um olhar ímpar para não deixar essas mudanças interfiram de maneira a complicar ainda mais o estado de saúde do cliente (Depianti, 2014).

A criança tem o direito de brincar e, mesmo no ambiente hospitalar, esse direito não pode ser suprimido. Com relação ao brincar, necessita-se que os profissionais de saúde ofereçam condições humanizadas para essa ação, mesmo que existam dificuldades físicas, o brincar dever ser pensado e oferecido de forma singular à criança. Os profissionais de enfermagem vêm reconhecendo à relevância do brinquedo terapêutico como um novo meio de comunicação, com o intuito de ajudar a criança a aceitar melhor a sua internação e adaptação ao ambiente hospitalar (Francischinelli; Almeida; Fernandes, 2012).

Entendendo que o tratamento para o câncer repercute no cotidiano da criança, nos hábitos, gera tristeza, medo e incerteza do que ainda vem pela frente. $\mathrm{O}$ suporte emocional e as estratégias para adaptar essa criança ao ambiente hospitalar são imprescindíveis e contribuem de forma positiva para uma melhor reação e reestruturação do aspecto psicoemocional da criança.

De acordo com as falas das entrevistadas, a seguir, desmonta que os profissionais exercem seu trabalho de forma humanizada como é preconizado pelo programa de humanização no cuidado às crianças com leucemia. 
Research, Society and Development, v. 10, n. 3, e14410313142, 2021

(CC BY 4.0) | ISSN 2525-3409 | DOI: http://dx.doi.org/10.33448/rsd-v10i3.13142

A gente sempre trabalha com todas de forma humanizada, a gente tanto acode a criança como a familiar, com a mãe, o pai, que sempre tão acompanhando. E ás vezes o que a gente tem mais dificuldade é de lidar com eles, por que eles são mais e muito ansiosos, muito preocupados com o tratamento em si da criança, levando em consideração ao diagnóstico. (E01)

A ansiedade e a preocupação, descritas nos relatos acima com relação ao tratamento é, também, apontada na literatura. De acordo com Loggeto, Park e Braga, (2012) a ação do tratamento farmacológico antineoplásico é imediata. Os medicamentos causam alterações no organismo como um todo. Dois exemplos são a diarreia e a constipação, a primeira causada por consequência ao uso de medicações, infecções, mudança de hábitos alimentares e ansiedades. A segunda, causada pela a utilização de alguns medicamentos específicos que acabam constipando a criança.

As sensações e os sentimentos desagradáveis provocados pelo ambiente novo, a hospitalização infantil, geralmente são potencializados que a equipe de saúde não está preparada para prestar uma assistência humanizada e condizente com o universo da criança. Logo, atuar com indiferença na realização dos procedimentos piora este contexto, dificultando o processo de adaptação da criança do ambiente e, consequentemente, sua adesão ao tratamento (Souza et al., 2013b).

A interação com a criança sem a utilização de maios de comunicação condizentes com seu universo como, por exemplo, realização de atividades lúdicas e intervenções educativas, podem ser interpretadas pelo binômio criança/família como uma postura negativa do profissional de saúde, falta de conhecimento ou humanização em sua assistência (Souza et al., 2013b). Portanto, esse tipo de atitude deve ser evitado para o bem-estar dos indivíduos que estão inseridos nesse contexto e adesão das crianças às medicas terapêuticas.

Mas é conversa, conversa com a criança, identificação dela ne, para não ter que errar medicação, pulseirinha, mais não tem cuidado especifico não, mais é essa parte de conversar com a mãe, brincar, acalmar, não tem acolhimento especifico, ainda mais eu que sou da noite, aí é que eu não vejo esse povo mesmo, o que as outras enfermeiras responderam? Só vou lá quando tem intercorrência. (E02)

As medidas de segurança do paciente são descritas na narrativa acima (E02), como a identificação do paciente e controle da administração de medicamos. Ações importantíssimas, realizas pela enfermagem para o controle de eventos adversos.

A narrativa (E02), destaca um profissional do turno da noite, o qual descreve não estar ao lado das crianças em todos os momentos. Cita que vai ao encontro da criança em caso de alguma intercorrência. Demostrando assim, um descompasso a assistência integral e acolhedora.

No momento da internação a gente antecipar as coisas que vão acontecer, para a criança já poder ir se preparando pro que vem pela frente então, com a psicóloga, com a fisioterapeuta, eu como enfermeira e as técnicas também todo mundo é orientado a fazer isso pra criança ir aceitando aos poucos, é difícil pra criança, mais a gente vai explicando aos pouquinhos ai a gente consegue ter uma relação boa, só que eles ficam muito triste. (E03)

O discurso acima evidencia a fragilidade da família e das crianças após o impacto do diagnóstico. Sendo assim, um dos primeiros sentimentos que surge durante esse processo inicial é o sentimento de perda, desde o início do tratamento que podem ter uma reação à negação, à angústia e a depressão, pelo fato de ter a esperança da melhora do ente querido. As 
orientações quanto aos procedimentos a serem realizados, sempre com antecedência, é uma estratégia da equipe de enfermagem em amenizar essa fragilidade.

Souza et al. (2012) explicitam que no ambiente hospitalar a criança é exposta à situações atípicas e forçadas a adaptarse a elas. É destituída dos seus pertences, despida, banhada e vestida com roupas do hospital. Adentra em um ambiente novo, com pessoas desconhecidas, com todas as particularidades do ambiente.

Nesse caso a interação com a criança é importante, por que ganhando a confiança, elas têm uma melhor aceitação de medicações então nesse caso elas podem ter uma recuperação mais rápida. (T01)

A interação com a criança, o desenvolvimento da confiança da mesma para com o profissional de saúde desencadeia a adaptação e a esperança de resultado positivo para a doença. Essas ações são grandes armas para o enfrentamento do tratamento. São essenciais na superação do estresse físico e emocional advindos da quimioterapia (Souza et al., 2012).

Resumindo, meu amor bora começar logo, quanto mais cedo mais rápido termina é desse jeito é como eu disse, é tentar esquecer que ele ta num hospital e fazer com que tipo assim, não é enganar, eu não engano ninguém, pode ser criança, mais sempre digo a verdade, olha a tia vai ter que te furar, vai doer meu amor, mais é uma beliscada, eu não vou mentir vai doer então você seja mais forte do que eu porque eu sou super medrosa, eles ficam mais forte do que eu. (T02)

[...] Assim um pouco complicado, quem tem mais assim esse manejo é quem trabalha de dia, tendo mais assim um pouco de apoio, conversando tentando interagir com a própria criança ,já tem a sala de brinquedos que eles frequenta, tem a psicologia, as vezes quando a gente detecta alguma coisa, alguma aceitação, a gente já entra em contato com a psicóloga, fala pra enfermeira, e assim a gente, no meu ponto de vista no que a gente pode ajudar assim em algum esclarecimento de muitas curiosa, assim no resultado de exame, de hemograma, essas coisas, mesmo que não entenda a gente pega, dá o prontuário amostra, e tudo, ninguém barra, por que ela já quer ver, já tem acesso, então a gente já deixa mesmo que não saiba [...]. (T03)

Nas falas de T02 e T03 observa-se o empenho em tratar às crianças de forma humanizada, realizando todas as orientações que às crianças necessitam, levando também em consideração o lado emocional e a questão de apoiar a presença da família no momento dos cuidados.

[...] Tem criança que é a primeira internação que descobrem o diagnostico eles chegam, os pais chegam mesmo naquele modelo, sem noção, sem chão a gente já, como a gente já fica muito tempo que eles o pessoal fica doze horas, a gente observa mais como é que ta a família ai no outro dia a gente diz pra psicóloga da uma olhadinha ai é aquela coisa, mais também tem dias que a gente fica vinte minutos na enfermaria deles, por que elas começam a conversar que faz é pena a gente deixar, eu acho que sou a mais besta que fico[...]. [...] ai elas ficam tirando dúvidas principalmente as de primeira internação, mas ai sempre é bom ficar conversando com eles. (T04)

Com isso, segundo a fala da T04 é importante que a equipe de enfermagem não se limite apenas às rotinas impostas pelo setor de oncologia, mas também agregue conhecimento e uma postura reflexiva para agir da melhor forma frente às 
Research, Society and Development, v. 10, n. 3, e14410313142, 2021

(CC BY 4.0) | ISSN 2525-3409 | DOI: http://dx.doi.org/10.33448/rsd-v10i3.13142

diversas situações, uma vez que a orientação adequada aos cuidados das crianças consolida a profissão de enfermagem e gera assim maior emancipação no local de trabalho.

Assim elas vão mais vendo pela questão das outras, vai vendo a questão das outras vai vendo aquela visão da queda do cabelo, tem umas que ficam bem chorosas, ai elas vão vendo as outras e vão aceitando entre aspas e também as mais ficam bem apreensivas. (T05)

A enfermagem é a categoria que está diretamente ligada aos cuidados diários ao paciente. O Cuidado prestado por essa categoria é relevante para a recuperação da criança, pelo fato de ela estar mais próximo a ela e à família, e ter uma visão mais aberta às necessidades de saúde dessa clientela. A família também possui posição importante na promoção da saúde e, por isso, torna-se indispensável que o profissional de saúde dê valor a sua opinião, escute suas dúvidas e estimule sua participação em todo o processo de cuidar, durante a hospitalização (Xavier, Gomes, Barlem \& Erdmann, 2013).

Os familiares são pessoas importantes no apoio emocional em todo o processo de adoecimento da criança, portanto devem ser encorajados e receberem cuidados e instruções de o quão eles podem ajudar na recuperação do ente querido. $\mathrm{O}$ apoio emocional da família representa força, ânimo e coragem, para essas crianças.

[...] A gente combina, hora que tem o medicamento tal, que é o antibiótico do horário de horas, mãezinha tem o medicamento dez horas, então tu pode ir pra sala de brinquedo, de oito as nove e meia, quando for dez horas tu chega aqui pra fazer o antibiótico, ai assim a gente combina com eles nos horários da medicação eles estão aqui rente, é bem assim, e a gente tem que tem ter, na hora de fazer algum tipo de procedimento por exemplo, eu trabalho com os pequenininhos ali, pra fazer a inalação é hiper,mega difícil né, ai eu faço um seguinte, mãezinha na hora que ele tiver dormindo tu me chama que nos duas vamos fazer a inalação dele, ai na hora que ele dorme a gente vai lá, faz a inalação, eu procuro respeitar o horário deles também, juntamente com o horário do hospital, num intervalozinho que ele dá um cochilo ai vamos lá fazer a inalação ou fazer algum medicação que ele não ta aceitando, na hora das punções não vem só uma puncionar, vem duas por que precisa botar um videozinho pra eles cantarem, pra alegrarem ele pra poder aceitar a hidratação por que se não é difícil. (T06)

No relato acima (T06), evidencia que a equipe de enfermagem presta cuidados às crianças com leucemia com relação a administração de medicamentos, procurando fazer com que o acompanhante entre numa rotina hospitalar de horários para medicação e para o lazer da criança. Outro fator indispensável é manter o acompanhante sempre informado sobre a patologia e sobre os fatos que estão ocorrendo no momento com a criança.

Com relação aos horários de lazer da criança, destaca-se que o ato de brincar no contexto hospitalar constituiu um recurso de comunicação viável e adequado que pode ser utilizado pela equipe de enfermagem pediátrica, com o intuito não somente de possibilitar a criança para se descontrair, mas uma estratégia para ela possa se expressar (Souza et al., 2012).

A gente explica pra ela, brinca também um pouco, a gente mostra vídeo pra ela, dá balão pra ela com luvas, eu no caso no lugar dos acessos eu faço desenhos nos acessos pra elas aceitarem mais a troca de acessos que é de três em três dias, mais são ótimas as crianças daqui, não existe não, só tu conhecendo mesmo, tem um aqui de um ano que não dá um pingo de trabalho pra pegar acesso, não chora. (T07) 
Research, Society and Development, v. 10, n. 3, e14410313142, 2021

(CC BY 4.0) | ISSN 2525-3409 | DOI: http://dx.doi.org/10.33448/rsd-v10i3.13142

Os profissionais de saúde entrevistados demostram preocupação e utilização do acolhimento como estratégia para dar uma assistência de qualidade para as crianças e seus acompanhantes, respeitando todos os significados desse momento. Elas proporcionaram uma criação de vínculo, transmitindo confiança, tranquilidade e garantiram os direitos das crianças preconizados pelo Ministério da Saúde.

\section{Conclusão}

A pesquisa possibilitou a ampliação dos conhecimentos sobre os cuidados prestados pela equipe de enfermagem às crianças com leucemia, evidenciando a maneira como são prestados. Essa pesquisa contribui para a reflexão dos principais pontos a serem considerados quando se trata de cuidado à criança e, quando se deseja uma assistência integrada e sistematizada, a fim de proporcionar melhor qualidade de vida para essa população no ambiente hospitalar.

A relevância da pesquisa está em identificar as ações de enfermagem no cuidado à criança com leucemia e proporcionar sua discussão e implementação na assistência em outras instituições de saúde.

\section{Referências}

Andrade, V., Sawada, N. O., \& Barichello, E. (2013). Qualidade de vida de pacientes com câncer hematológico em tratamento quimioterápico. Revista da Escola de Enfermagem da USP, 47(2), 355-361.

Barbeiro, F. M. S. (2013). Sentimentos evidenciados pelos pais e familiares frente ao diagnóstico de câncer na criança. Rev pesqui cuid Fundam (Online), 162172 .

Bellesso, M. (2013). Febrile neutropenia studies in Brazil: treatment and cost management based on analyses of cases. Revista brasileira de hematologia e hemoterapia, 35(1), 3-4.

Cunha, C. M., Ferreira, T. C., Oliveira Morales, N. M., Morales, R. R., Pinto, R. M. C., \& da Silva, C. H. M. (2013). nfluência dos tipos de câncer pediátrico e das fases do tratamento na qualidade de vida dos cuidadores. Bioscience Journal, 29(3).

Demirbag, B. C., Kurtuncu, M., \& Guven, H. (2013). Knowledge of Turkish mothers with children in the 0-13 age group about cancer symptoms. Asian Pacific Journal of Cancer Prevention, 14(2), 1031-1035.

Depianti, J. R. B., Silva, L. F., Monteiro, A. C. M., \& Soares, R. S. (2014). Dificuldades da enfermagem na utilização do lúdico no cuidado à criança com câncer hospitalizada. Revista de Pesquisa: Cuidado e Fundamental, 6(3).

Duarte, M. D. L. C., Zanini, L. N., \& Nedel, M. N. B. (2012). O cotidiano dos pais de crianças com câncer e hospitalizadas. Revista Gaúcha de Enfermagem, 33(3), 111-118.

Espinoza, K., \& Jofre, V. Sobrecarga, apoyo social y autocuidado en cuidadores informales. Cienc Enferm. $2012 ; 18$ (2): 23-30.

Francischinelli, A. G. B., Almeida, F. D. A., \& Fernandes, D. M. S. O. (2012). Uso rotineiro do brinquedo terapêutico na assistência a crianças hospitalizadas: percepção de enfermeiros. Acta Paulista de Enfermagem, 25(1), 18-23.

Gurgel, L. A., \& Lage, A. M. V. (2013). Atuação psicológica na assistência à criança com câncer: da prevenção aos cuidados paliativos. Rev Psicol, 4(1), 8396.

Loggeto, S. R., Park, M.V.F., \& Braga, J.A.P. (2012). Oncologia para o pediatra. Atheneu, 2012.

Maestri, E., Nascimento, E. R. P., Bertoncello, K. C. G., \& Jesus Martins, J. (2012). Estratégias para o acolhimento dos familiares dos pacientes na unidade de terapia intensiva. Rev enferm UERJ, 20(1), 73-78.

Maranhão, T. A., Melo, B. M. D. S., Vieira, T. S., Veloso, A. M. V., \& Batista, N. N. L. A. (2011). A humanização no cuidar da criança portadora de câncer: fatores limitantes e facilitadores. J Health Sci Inst, 29(2), 106-9.

Matias, S. R. (2016). Assistência de enfermagem às crianças com leucemia Linfoblástica aguda (lla). 17f. Trabalho de conclusão de curso (Bacharel em Enfermagem) - Centro Universitário São Lucas, Porto Velho.

Ministério da Saúde, Brasil. (2012). Instituto Nacional do Câncer (INCA). Estimativa 2012: incidência de câncer no Brasil. Rio de Janeiro: INCA. Available from: 〈http://www.inca.gov.br/estimativa/2012.pdf〉. Acesso em: 22 jun. 2017.

Ministério da Saúde, Brasil. (2013). Leucemia. Rio de Janeiro: INCA. <http://www2.inca.gov.br/wps/wcm/connect/tiposdecanc er/site/home/leucemia/definicao>.

Ministério da Saúde, Brasil. (2016). Particularidades do câncer infantil. Rio de Janeiro: INCA. 
Research, Society and Development, v. 10, n. 3, e14410313142, 2021

(CC BY 4.0) | ISSN 2525-3409 | DOI: http://dx.doi.org/10.33448/rsd-v10i3.13142

Mutti, C. F., Mello Padoin, S. M., Paula, C. C., Oliveira Souza, I. E., Terra, M. G., \& Quintana, A. M. (2012). Cuidado de enfermagem à criança que tem doença oncológica avançada: ser-com no cotidiano assistencial. Ciência, cuidado e saúde, 11(1), 113-120.

Pereira, A. R. P. D. F., Matsue, R. Y., Vieira, L. J. E. D. S., \& Pereira, R. V. S. (2014). Análise do cuidado a partir das experiências das mães de crianças com paralisia cerebral. Saúde e Sociedade, 23, 616-625.

Ribeiro, J. P., Gomes, G. C., \& Thofehrn, M. B. (2014). Ambiência como estratégia de humanização da assistência na unidade de pediatria: revisão sistemática. Revista da Escola de Enfermagem da USP, 48(3), 530-539.

Silva, J. K. O., Moreira-Filho, D.C., Mahayri, N., Ferraz, R.O. (2012). Childhood câncer: information followed in population-based câncer registry. Rev bras cancerol, 58(4), 681-686.

Silva, M. E. D.C., Costa, L. D., Dantas, A. L. B., Araújo, D. O. R., Duarte, I. S., \& Sousa, J. F. M. (2013). Nursing care to cancer patients in the hospital/Assistência de enfermagem ao paciente oncológico no hospital. Revista de Enfermagem da UFPI, 2(5), 69-75.

Silva, R. C. F. D., \& Hortale, V. A. (2006). Cuidados paliativos oncológicos: elementos para o debate de diretrizes nesta área. Cadernos de saúde pública, 22(10), 2055-2066.

Souza, B. F. D., Pires, F. H., Dewulf, N. D. L. S., Inocenti, A., Silva, A. E. B. D. C., \& Miasso, A. I. (2013a). Patients on chemotherapy: depression and adherence to treatment. Revista da Escola de Enfermagem da USP, 47(1), 61-68.

Souza, L. F. D., Misko, M. D., Silva, L., Poles, K., Santos, M. R. D., \& Bousso, R. S. (2013). Morte digna da criança: percepção de enfermeiros de uma unidade de oncologia. Revista da Escola de Enfermagem da USP, 47(1), 30-37.

Souza, L. P., Silva, R. K. P., Amaral, R. G., Souza, A. A. M., Mota, É. C., \& Oliveira, C. S. (2012). Câncer infantil: sentimentos manifestados por crianças em quimioterapia durante sessões de brinquedo terapêutico. Revista da rede de enfermagem do Nordeste, 13(3), 686-692.

Viero, V., Beck, C. L. C., Freitas, P. H., Coelho, A. P. F., Lima, S. B. S., \& Machado, B. P. (2014). Enfrentamentos da criança com câncer frente ao afastamento escolar devido internação hospitalar. Revista de Enfermagem da UFSM, 4(2), 368-377.

Xavier, D. M., Gomes, G. C., Barlem, E. L. D., \& Erdmann, A. L. (2013). A família revelando-se como um ser de direitos durante a internação hospitalar da criança. Revista Brasileira de Enfermagem, 66(6), 866-872. 